\title{
Cytohistological correlation and discrepancy of conventional Papanicolaou smear test with corresponding histopathology: a retrospective study over a 5-year period
}

N.Y. Alwahaibi, ${ }^{1}$ S. K. Al Sulimi ${ }^{1}$ and U.R. Bai ${ }^{1}$

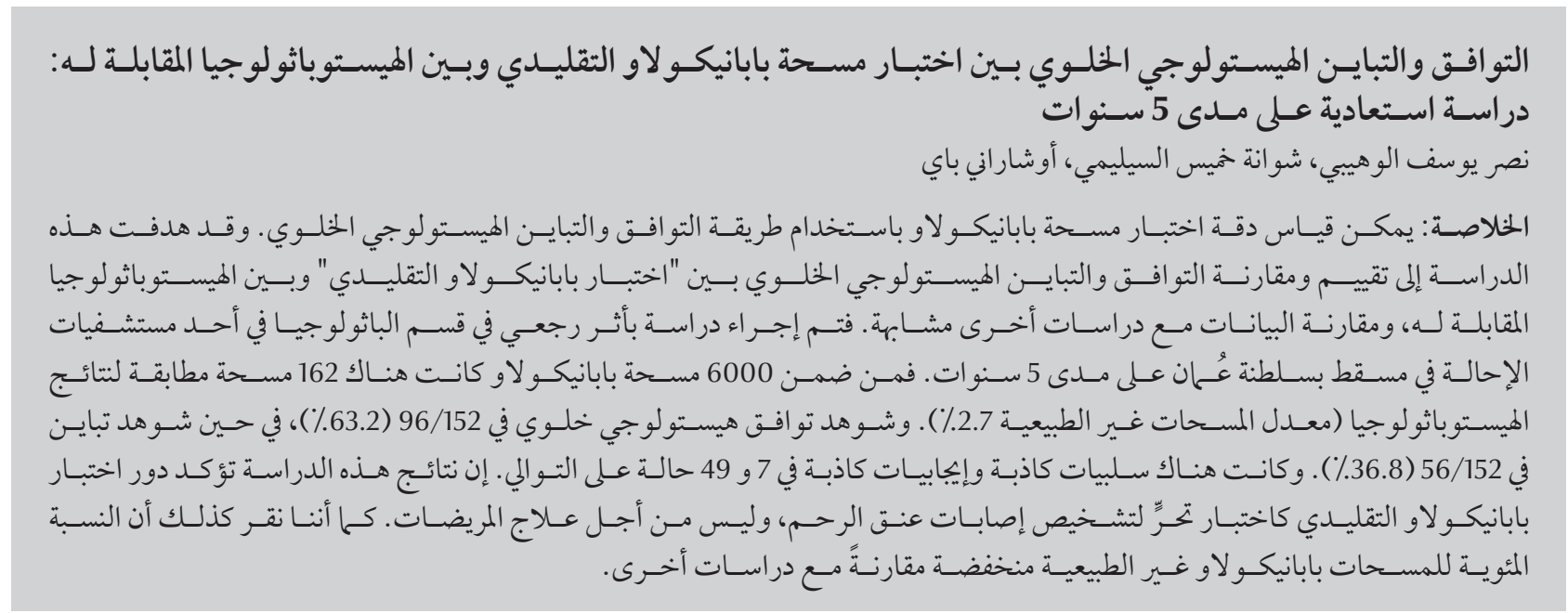

ABSTRACT The accuracy of Papanicolaou (Pap) smear testing can be measured using the cytohistological correlation and discrepancy method. This study aimed to evaluate and compare the cytohistological correlation and discrepancy of the conventional Pap test with the corresponding histopathology and to compare the data with other similar studies. A retrospective study was performed at the pathology department of a referral hospital in Muscat, Oman, over a 5-year period. Of 6000 Pap smears, 162 had matching histopathology results (abnormal smear rate $2.7 \%$ ) but 10 were unsatisfactory for histological diagnosis. Cytohistological correlation was seen in 96/152 (63.2\%), while discrepancy was seen in 56/152 (36.8\%). False negatives and false positives were found for 7 and 49 cases respectively. The findings of this study confirm the role of conventional Pap testing as a screening test for the diagnosis of cervical lesion but not for management of patients. In comparison with other studies, we also report a low percentage of abnormal Pap smears.

Corrélation et discordance cytohistologiques entre le test de Papanicolaou classique et I'histopathologie correspondante : étude rétrospective sur une période de cinq ans

RÉSUMÉ L'exactitude du test de Papanicolaou classique peut être mesurée à l'aide de la méthode de la corrélation et de la discordance cytohistologiques. La présente étude visait à évaluer et à comparer la corrélation et la discordance cythohistologiques du test de Papanicolaou classique à l'histopathologie correspondante et à comparer les données à celles d'autres études similaires. Une étude rétrospective a été menée dans le service de pathologie d'un hôpital de recours à Mascate (Oman), sur une période de cinq ans. Sur un total de 6000 frottis vaginaux, 162 présentaient des résultats histopathologiques concordants (taux de frottis anormaux : 2,7\%) mais 10 d'entre eux n'étaient pas satisfaisants pour le diagnostic histologique. Une corrélation cytohistologique a été observée dans 96/152 des cas (63,2 \%), tandis qu'une discordance a été observée pour 56/152 cas (36,8\%). Des faux négatifs et des faux positifs ont été observés dans 7 cas et 49 cas, respectivement. Les résultats de cette étude confirment le rôle du test de Papanicolaou classique en tant que test de dépistage pour le diagnostic d'une lésion cervicale mais pas pour la prise en charge des patientes. Par rapport à d'autres études, nous avons aussi observé un faible pourcentage de frottis vaginaux anormaux. 


\section{Introduction}

After breast cancer, cervical cancer is the second most common cancer in women worldwide and considered to be the major cause of death from malignancy in women in developing countries (1-3). In Oman, cervical cancer is the third most common cancer in women with a rate of $6.3 \%$ (4). The main cause of increasing cervical cancer is not known. However, many studies report that exposure to human papilloma virus (HPV), active sexual life, multiparity, hormonal contraception, genetic factors and smoking may contribute to the initiation of cervical cancer $(5,6)$. Cervical cancer screening programmes play an important role in the reduction of cervical cancer in developed countries (7). However, in many developing countries cervical cancer screening programmes have not been implemented.

Despite the lack of a standardized method for the cytohistological correlation of cervical lesions, many studies show that this correlation gives a high detection rate (8-11). In fact, it is considered to be a method to detect medical error in the histopathology laboratory (12). This correlation evaluates the accuracy of cytological examination when false negative and false positive findings are present. Histopathologic examination is the gold standard. This correlation is also useful for continuous quality improvement, which is a must for many cytology laboratories, in particular, those laboratories that apply the Bethesda system in their diagnosis $(13,14)$. To our knowledge, this is the first study in Oman to evaluate and compare the cytohistological correlation and discrepancy of conventional Papanicolaou (Pap) smear testing with the corresponding histopathology and to compare the findings with other similar studies.

\section{Methods}

\section{Study design and setting}

A retrospective records review was performed of a period of 5 years from
January 2006 to December 2010 in the Department of Pathology, Sultan Qaboos University Hospital, which serves as tertiary referral hospital in Oman. The records of all patients who had conventional Pap smears were included. Of 6000 Pap smears recorded during the study period, 162 had matching histopathology records.

This study was conducted after an approval from the medical research committee and ethics committee (MREC \# 409) of the College of Medicine and Health Sciences, Sultan Qaboos University, Oman.

\section{Laboratory methods}

For Pap staining, 2 slides were fixed in $95 \%$ ethanol for $15 \mathrm{~min}$, followed by immediate dipping in 50\% ethanol for $2 \mathrm{~min}$. After that, the slides were washed in tapwater for 10 seconds. After the water was removed from the slides using tissue papers, the slides were kept in Harris haematoxylin stain for 1 min. Then the slides were washed in tap water until clear. The slides were then differentiated with $0.5 \%$ acid alcohol for 2-3 quick dips. The nuclear stain was checked under light microscope to ensure the clarity of the nuclei. The slides were washed in water for $10 \mathrm{~s}$ followed by 10 dips in 2 changes of $95 \%$ ethanol. Immediately, the slides were placed in OG-6 for $3 \mathrm{~min}$. The slides were dipped in 2 changes of $95 \%$ ethanol for 10 dips each. After that, the slides were placed in EA-50 for $4 \mathrm{~min}$. The slides were dipped in 3 changes of $95 \%$ ethanol for 10 dips each. Then, the slides were dipped in 3 changes of absolute ethanol for 10 dips each. The slides were dipped in 3 changes of xylene for 15 dips each. Finally, the slides were mounted in DPX synthetic resin.

For histopathologic diagnosis, cervical punch biopsies, cones or pieces of hysterectomy specimens were fixed in $10 \%$ neutral buffered formalin for 24 hours, histoprocessed, cut into $3 \mu \mathrm{m}$ thickness diameter and stained with haematoxylin and eosin method as follows: sections were stained with haematoxylin for $10 \mathrm{~min}$. The slides were then washed in running tap water. They were differentiated in $1 \%$ acid alcohol for 5 seconds and blued by immersing in Scott tap water for a few seconds. They were washed well in water. The nuclei were checked under the microscope for proper differentiation. The sections were stained with eosin for 5 min. Then, slides were washed in water. Next, they were dehydrated through graded alcohol, cleared in 2 changes of xylene and mounted in DPX.

\section{Cytological and histopathological diagnosis}

Cytology was performed by different available histopathologists over a period of 5 years. Cytological diagnosis was classified into 6 categories: unsatisfactory, borderline nuclear changes, mild dyskaryosis, moderate dyskaryosis, severe dyskaryosis and carcinoma. Histopathological diagnosis was also classified into 6 categories: unsatisfactory, benign, cervical intraepithelial neoplasia (CIN) 1, CIN 2, CIN 3 and carcinoma. Dyskaryosis in cytological diagnosis is equivalent to CIN in histological diagnosis. Thus, mild dyskaryosis is equivalent to CIN 1, moderate dyskaryosis to CIN2 and severe dyskaryosis to CIN 3.

\section{Results}

A total of 6000 gynaecological smears were found. The patient age range was $18-80$ years, with a mean age of 40.0 years. The frequency and percentage of various cytopathological findings are shown in Table 1.

Cervical smears with corresponding histopathology were found in 162 cases. Table 2 shows that $6.2 \%(10 / 162)$ cases were unsatisfactory for histological diagnosis, whereas $75(46.3 \%)$ cases were benign and only 8 (4.9\%) cases were carcinoma.

Cytohistological correlation was found for 96/152 (63.2\%) 


\begin{tabular}{lcc}
\hline Table 1 Cytopathological diagnosis of $\mathbf{6 0 0 0}$ cervical smears & \\
\hline Diagnosis & No. & $\%$ \\
Unsatisfactory & 320 & 5.3 \\
No malignancy & 5518 & 92.0 \\
Borderline nuclear changes & 64 & 1.1 \\
Mild dyskaryosis & 39 & 0.7 \\
Moderate dyskaryosis & 34 & 0.6 \\
Severe dyskaryosis & 11 & 0.2 \\
Carcinoma & 14 & 0.2 \\
Total & 6000 & 100.0 \\
\hline
\end{tabular}

cases, whereas discrepancy was found for $56 / 152(36.8 \%)$.

There were 7 (4.6\%) cases of false negatives. Three cases were misinterpreted as cells of borderline nuclear change in cytology and turned out to be CIN 2 in histopathology. The other 4 cases were reported to have severe dyskaryosis in cytology and turned out to be carcinoma in histopathology.

There were 49 (32.2\%) cases of false positives. The highest number (17) were seen in mild dyskaryosis which turned out to be benign in histopathology (Table 3).

\section{Discussion}

The sensitivity, specificity and accuracy of the Pap test were not measured in this study as we were unable to measure the true positives and true negatives in this study. As an alternative, the cytohistological correlation and discrepancy of Pap testing were measured. Many studies too have measured the accuracy of the Pap test using the same method $(15-21)$. We report $63.2 \%$ and $36.8 \%$ for the cytohistological correlation and discrepancy of Pap smears respectively. These findings are in line with the ranges reported in the literature from similar studies, i.e. $51.2-77.5 \%$ for cytohistological correlation and $22.5-48.8 \%$ for discrepant cases of Pap smears (15-19) (Table 4). The cytohistological correlation of this study showed that Pap testing was more sensitive in detecting borderline nuclear changes and CIN 1 than CIN 2 and 3 and carcinoma. This finding differs from other studies $(18,22)$.

False negative findings in the diagnosis of Pap smears is a major concern to patients, clinicians, cytoscreeners and cytopathologists. To a lesser extent, a false positive finding is less important than a false negative finding. In this study, we found a rate of $4.6 \%(7 / 152)$ and $32.2 \%(49 / 152)$ for false negative and false positive findings respectively. Another study reported a higher false positive rate of $43.0 \%(161 / 374)(15)$.

\begin{tabular}{lcc}
\hline Table 2 Histopathological diagnosis of $\mathbf{1 6 2}$ cervical smears & \\
Diagnosis & No. & $\%$ \\
Unsatisfactory & 10 & 6.2 \\
Benign & 75 & 46.3 \\
CIN 1 & 48 & 29.6 \\
CIN 2 & 15 & 9.3 \\
CIN 3 & 6 & 3.7 \\
Carcinoma & 8 & 4.9 \\
Total & 162 & 100.0 \\
\hline
\end{tabular}

$C I N=$ cervical intraepithelial neoplasia .

Most pathologists worldwide are better trained in histopathology examination than in cytological interpretation (23). Furthermore, it is noteworthy that tissue interpretation is easier than cytology preparations (24). The absence of specialized cytopathologists for the diagnosis of cervical lesions may contribute to the discrepancy. In our department, Pap smears are first screened by a cytotechnologist and if an abnormal smear is found then the histopathologist evaluates the smear. This procedure is applied worldwide $(15,25)$

Conventional Pap smears were used throughout this study. During conventional Pap smearing, drying artefacts, inadequate fixations, background materials and thick smears are frequently present. Another study reported that air drying artefacts were the main reason for the $72.7 \%$ discrepant cases they observed (16). These drawbacks increase interpretation errors. It has been reported that in liquid-based cytology, such as ThinPrep processor, AutoCyte PREPTM System or other similar processes, prevent air drying artefacts, have minimum background material and increase the cellularity is (26). In our department, the ThinPrep ${ }^{\circ}$ system was initiated only in 2012 and its application might have led to different outcomes.

Another study reported that specimen collection, handling, fixation, staining and the experience of the screener and cytopathologist may contribute to the false negative rate of Pap smear accuracy (18). It was outside the scope of this study to investigate the factors that may have contributed to the discrepancy.

The findings of this study showed that abnormal cases of Pap smear were 162 out of 6000 (2.7\%). This finding is consistent with data from the neighbouring country of Saudi Arabia, where 368 out of 22089 cases showed abnormal Pap smears (1.7\%) (21). Another recent Turkish study showed a similar 


\begin{tabular}{|c|c|c|c|c|c|c|c|}
\hline \multirow[t]{2}{*}{ Cytopathology findings } & \multicolumn{7}{|c|}{ Histopathology diagnosis } \\
\hline & Unsatisfactory & Benign & CIN 1 & CIN 2 & CIN 3 & Carcinoma & Total \\
\hline Unsatisfactory & 0 & 0 & 0 & 0 & 0 & 0 & 35 \\
\hline Borderline nuclear changes & 5 & 36 & 20 & 3 & 0 & 0 & 64 \\
\hline Mild dyskaryosis & 2 & 17 & 20 & 0 & 0 & 0 & 39 \\
\hline Moderate dyskaryosis & 2 & 13 & 7 & 10 & 2 & 0 & 34 \\
\hline Severe dyskaryosis & 0 & 1 & 0 & 2 & 4 & 4 & 11 \\
\hline Carcinoma & 1 & 8 & 1 & 0 & 0 & 4 & 14 \\
\hline Total & 10 & 75 & 48 & 15 & 6 & 8 & 162 \\
\hline
\end{tabular}

$C I N=$ cervical intraepithelial neoplasia .

\begin{tabular}{lcc}
\hline $\begin{array}{l}\text { Table } 4 \text { Comparison of cytohistological correlation and discrepancy of Pap testing } \\
\text { in the current study and other similar studies }\end{array}$ & & \\
\hline Study, year (reference) & Correlation & Discrepancy \\
& $\%$ & $\%$ \\
Current study & 63.2 & 36.8 \\
Abali et al., 2011 (15) & 57.0 & 43.1 \\
Gupta and Sodhani., 2004 (16) & 74.0 & 26.0 \\
Zuna et al., 2002 (17) & 62.7 & 37.3 \\
Sodhani et al., 1997 (18) & 77.5 & 22.5 \\
Yeoh et al., 1997 (19) & 51.2 & 48.8 \\
\hline
\end{tabular}

finding (3\%) (27). Overall, the rate of abnormal Pap smears in developing countries ranges between $1.5 \%$ and $6 \%$ (28). Also, our rates of mild dyskaryosis (0.7\%), moderate dyskaryosis (0.6\%), severe dyskaryosis $(0.2 \%)$ and carcinoma $(0.2 \%)$ are close to the findings of another study performed in Saudi Arabia, where rates of $0.28 \%, 0.2 \%, 0.12 \%$ and $0.09 \%$ were reported, respectively (21). In comparison with developed countries, the prevalence of CIN 1 in USA and Australia were 2.6\% and 5.6\% respectively $(29,30)$. Thus, the grades of cervical lesion are low in our study. A total of 320 (5.3\%) out of 6000 cases were reported as unsatisfactory for cytological diagnosis. This could be due to sampling errors, air drying artefacts or obscuring blood and inflammatory cells.

Worldwide, histological examination is considered to be the gold standard for the diagnosis of cervical lesion (31). In comparison with histopathological examination, cytological examinations have many advantages. First, the disease progression can be monitored simply. Secondly, the procedure is not invasive. Thirdly, repeat specimens can be obtained easily. Finally, the diagnosis is fast. However, there is a concern about the accuracy of cytopathological reports (32). Thus, in our hospital, the cytological report is useful in pre-diagnosis of early malignancy but not for the management of patients. Confirmation by cervical biopsy is essential in the treatment of patients. In this study, histological examinations were graded using the CIN system, whereas Pap smears were graded using the British system for cervical diagnosis. These 2 systems do not correlate exactly. Even with the 2001 Bethesda system, variations are present in both systems (12).

We should point out some weaknesses in this study. First, this study was performed in one hospital, which is located in the capital city of Oman, Muscat. Thus, we cannot generalize the data to all Omani women, especially those who live in the rural areas, where cervical cancer rates are usually high. Secondly, the absence of a cytoscreener and histopathologist experience, which might contribute to the false negative and false positive findings in this study. Thirdly, sampling and interpretation errors were not evaluated. Finally, all Pap smears were performed using conventional methods; the use of monolayer preparations might have given different findings.

\section{Conclusions}

The findings of this study — slightly high cytohistological correlation, slightly low cytohistological discrepancy, a low false negative rate and high false positive rate-confirm the role of conventional Pap test as a screening test for the diagnosis of cervical lesions but not for the management of patients. In comparison with other studies, we also report a low percentage of abnormal Pap smears.

\section{Acknowledgements}

We would like to thank all staff in Pathology Department at Sultan Qaboos University Hospital, Muscat, Oman, for their cooperation and help in providing the data.

Funding: None.

Competing interests: None declared. 


\section{References}

1. Ferlay J, Bray F, Pisani P, Parkin DM. GLOBOCAN 2000: cancer incidence, mortality and prevalence worldwide. Version 1.0. IARC Cancer Base No. 5. Lyon: International Agency for Research on Cancer; 2001.

2. Al Sairafi M, Mohamed FA. Knowledge, attitudes, and practice related to cervical cancer screening among Kuwaiti women. Med Princ Pract. 2009;18(1):35-42. PMID:19060489

3. Jemal A, Bray F, Center MM, Ferlay J, Ward E, Forman D. Global cancer statistics. CA Cancer J Clin. 2011 Mar-Apr;61(2):69-90. PMID:21296855

4. NooyiSC, Al-LawatiJA. Cancerincidence in Oman,1998-2006. Asian Pac J Cancer Prev. 2011;12(7):1735-8. PMID:22126555

5. Muñoz N, Bosch FX, de Sanjosé S. The causal link between human papillomavirus and invasive cervical cancer: a population based case-control study. Int J Cancer. 2006;119:1108-24. PMID:16570271

6. Parkin DM, Bray Fl, Devesa SS. Cancer burden in the year 2000. The global picture. Eur J Cancer. 2001 Oct;37 Suppl 8:S4-66. PMID:11602373

7. Gustafsson L, Pontén J, Zack M, Adami HO. International incidence rates of invasive cervical cancer after introduction of cytological screening. Cancer Causes Control. 1997 Sep;8(5):755-63. PMID:9328198

8. Raab SS, Grzybicki DM, Zarbo RJ, Jensen C, Geyer SJ, Janosky $\mathrm{JE}$, et al. Frequency and outcome of cervical cancer prevention failures in the United States. Am J Clin Pathol. 2007 Nov;128(5):817-24. PMID:17951205

9. Joste NE, Wolz M, Pai RK, Lathrop SL. Noncorrelating Pap tests and cervical biopsies: histological predictors of subsequent correlation. Diagn Cytopathol. 2005 May;32(5):310-4. PMID:15830356

10. Clary KM, Silverman JF, Liu Y, Sturgis CD, Grzybicki DM, Mahood LK, et al. Cytohistologic discrepancies: a means to improve pathology practice and patient outcomes. Am J Clin Pathol. 2002 Apr;117(4):567-73. PMID:11939731

11. Jones BA, Novis DA. Follow-up of abnormal gynecologic cytology: a college of American pathologists Q-probes study of 16132 cases from 306 laboratories. Arch Pathol Lab Med. 2000 May;124(5):665-71. PMID:10782145

12. Raab SS, Grzybicki DM. Cytologic-histologic correlation. Cancer Cytopathol. 2011 Oct 25;119(5):293-309. PMID:21732549

13. Cioc AM, Julius CJ, Proca DM, Tranovich VL, Keyhani-Rofagha S. Cervical biopsy/cytology correlation data can be collected prospectively and shared clinically. Diagn Cytopathol. 2002 Jan;26(1):49-52. PMID:11782088

14. Mulligan NJ, de las Morenas A, Soto-Wright V, O'Brien MJ. Percentages of cervical cytologic diagnoses as a quality assurance method. Acta Cytol. 1998 Jul-Aug;42(4):928-32. PMID:9684579

15. Abali R, Bacanakgı BH, Celık S, Aras O, Koca P, Boran B, et al. Histopathological correlation of squamous cell abnormalities detected on cervical cytology. Turk Patoloji Derg. 2011 May;27(2):144-8. PMID:21630201

16. Gupta S, Sodhani P. Why is high grade squamous intraepithelial neoplasia under-diagnosed on cytology in a quarter of cases? Analysis of smear characteristics in discrepant cases. Indian J Cancer. 2004 Jul-Sep;41(3):104-8. PMID:15472407

17. Zuna RE, Sienko A, Lightfoot S, Gaiser M. Cervical smear interpretations in women with a histologic diagnosis of severe dysplasia: factors associated with discrepant interpretations. Cancer. 2002 Aug 25;96(4):218-24. PMID:12209663

18. Sodhani P, Singh V, Das DK, Bhambhani S. Cytohistological correlation as a measure of quality assurance of a cytology laboratory. Cytopathology. 1997 Apr;8(2):103-7. PMID:9134335

19. Yeoh GP, Chan KW. The accuracy of Papanicolaou smear predictions: cytohistological correlation of 283 cases. Hong Kong Med J. 1997 Dec;3(4):373-6. PMID:11847388

20. Moss EL, Moran A, Douce G, Parkes J, Todd RW, Redman CWE. Cervical cytology/histology discrepancy: a 4-year review of patient outcome. Cytopathology. 2010 Dec;21(6):38994. PMID:20482721

21. Jamal A, Al-Maghrabi JA. Profile of Pap smear cytology in the Western region of Saudi Arabia. Saudi Med J. 2003 Nov;24(11):1225-9. PMID:14647558

22. Soost HJ, Lange HJ, Lehmacher W, Ruffing-Kullmann B. The validation of cervical cytology. Sensitivity, specificity and predictive values. Acta Cytol. 1991 Jan-Feb;35(1):8-14. PMID:1994641

23. Alwahaibi N, Alfahdi HA, Bai UR. Fine needle aspiration cytology of 108 breast lesions with histopathologic correlation: a retrospective study. Annu Res Rev Biol. 2014;4(21):3244-50.

24. Oyama T, Koibuchi Y, McKee G. Core needle biopsy (CNB) as a diagnostic method for breast lesions: comparison with fine needle aspiration cytology (FNA). Breast Cancer. 2004;11(4):339-42. PMID:15604988

25. Colgan TJ, Woodhouse SL, Styer PE, Kennedy M, Davey DD. Reparative changes and the false-positive/false-negative Papanicolaou test: a study from the College of American Pathologists Interlaboratory Comparison Program in Cervicovaginal Cytology. Arch Pathol Lab Med. 2001 Jan;125(1):134-40. PMID:11151067

26. Kontzoglou K, Moulakakis KG, Konofaos P, Kyriazi M, Kyroudes A, Karakitsos P. The role of liquid-based cytology in the investigation of breast lesions using fine-needle aspiration: a cytohistopathological evaluation. J Surg Oncol. 2005 Feb 1;89(2):75-8. PMID:15660372

27. Çakmak B, Köseoğlu DR. Comparison of cervical cytological screening results between postmenopausal and elderly women. Turk Patoloji Derg. 2014;30(1):38-42. PMID:24448705

28. Sigurdsson K, Sigvaldason H. Longitudinal trends in cervical cytological lesions and the effect of risk factors. A 30-year overview. Acta Obstet Gynecol Scand. 2006;85(3):350-8. PMID:16553185

29. Richart RM. Influence of diagnostic and therapeutic procedures on the distribution of cervical intraepithelial neoplasia. Cancer. 1966 Nov;19(11):1635-8. PMID:5925272

30. Evans S, Dowling K. The changing prevalence of cervical human papilloma virus infection. Aust N Z J Obstet Gynaecol. 1990 Nov;30(4):375-7. PMID:1964552

31. DiBonito L, Falconieri G, Tomasic G, Colautti I, Bonifacio D, Dudine S. Cervical cytopathology. An evaluation of its accuracy based on cytohistologic comparison. Cancer. $1993 \mathrm{Nov}$ 15;72(10):3002-6. PMID:8221568

32. Morrison WB, DeNicola DB. Advantages and disadvantages of cytology and histopathology for the diagnosis of cancer. Semin Vet Med Surg (Small Anim). 1993 Nov;8(4):222-7. PMID:8303097 